\title{
Prevalence of Dental Anomalies among Schools Children in Sana'a City, Yemen
}

\author{
Khaled A. AL-Jawfi * , Mohammed A. BA-Salama** \\ *Assistant Professor of Oral Pathology, Oral Pathology Unit, Department of Dental Biomedical \& \\ Preventive Sciences, Faculty of Dentistry, University of Science \& Technology, Sana'a, Yemen. \\ ** Lecturer of Pedodontics, Department of Restorative Dentistry, Faculty of Alfarabi for Dentistry, \\ Ryadh, Kingdom of Saudi Arabia.
}

aljawfi1970@yahoo.com

\begin{abstract}
:
Objective: This study was designed to determine the relation of gender and systemic causes with dental anomalies.

Methods: This study was conducted on (1000) of schools children,(500) boys and (500) girls with an age ranged from 4-12 years. The sample was collected from five private and four public schools at Sana'a city, Yemen. Children were examined at schools, under natural day light with a disposable mouth mirrors, using gloves and gauze pads.

Results: Enamel hypoplasia (2.8\%) was the most prevalent dental anomalies, followed by enamel hypocalcification (2.6\%), then microdontia (0.5\%), after that macrodontia and hypodontia $(0.4 \%)$, then supernumerary teeth and dental transposition (0.3\%), and finally dental fusion and gemination $(0.2 \%)$.

Conclusion: The frequency of dental anomalies among schools children was in boys more than girls. Enamel hypoplasia was the commonest dental anomaly, while the lowest dental anomalies were dental fusion and gemination.
\end{abstract}

Keywords: Dental Anomalies, School Children, Sana'a City, Yemen.

\section{INTRODUCTION}

Developmental dental anomalies are an important category of dental symptomatology. Their incidence and degree of expression can provide important information for phylogenic and genetic studies and help the understanding of variations within and between populations. ${ }^{(1)}$ They are frequently observed during routine dental examinations, so early identification of a treatable anomaly is important in planning comprehensive management of the young child, and may help to recognize some systemic disease. ${ }^{(2,3)}$

Dental anomalies may be due to abnormalities in the differentiation of the dental lamina and the tooth germs(anomalies in number, size and shape) or to abnormalities in the formation of the dental hard tissues (anomalies in structure). ${ }^{(4)}$

Dental fusion is defined as the merging of two adjacent teeth forming an enlarged clinical crown. ${ }^{(\mathbf{5}-\mathbf{8})}$ Fused teeth are more occurred in the deciduous than in the permanent dentition. They are higher in the anterior region. $^{(5)}$

Dental gemination is known as an attempt of the division of a dental germ resulting in an incomplete formation of two teeth. ${ }^{(4,9)}$ Geminated teeth are more frequently in primary than in permanent dentition. They are higher in the maxillary primary incisors and the canines. ${ }^{(\mathbf{1 0 - 1 2})}$

Dental transposition is a rare dental anomaly and characterized by the interchanged position of two adjacent permanent teeth in the same quadrant or ectopic eruption of one tooth in the place of another. ${ }^{(\mathbf{1 3})}$ The maxillary canine is the most commonly involved tooth. In most of the cases canine changes its eruptive place with a lateral incisor or a first premolar. ${ }^{(14)}$

Supernumerary teeth or hyperdontia are the existing of additional teeth to the normal series in the dental arches, so can be classified as eumorphic or dysmorphic. Eumorphic supernumerary teeth have 
the same morphology of the normal teeth, whereas dysmorphic ones are small and conical or tuberculate. ${ }^{(15)}$ These teeth may remain embedded in the alveolar bone or can erupt into the oral cavity. The erupted supernumerary tooth might cause aesthetic and/or functional problems especially if it is situated in the maxillary anterior region. ${ }^{(16)}$

Hypodontia is defined as the congenital development in which one or more permanent teeth is absent ${ }^{(17)}$ However, anodontia, which represents the congenital absence of all teeth in the primary dentition and/or the permanent dentition, is a rare condition. The characteristic feature of the patient with anodontia is a senile facial appearance due to lack of all teeth and underdevelopment of the alveolar

ridges. $^{(\mathbf{1 8})}$

Macrodontia defined as abnormally large sized teeth, and may be due to a hereditary pattern. However, microdontia is literally "small teeth" when this condition is present. It commonly affects a single tooth, especially the maxillary lateral incisors. ${ }^{(\mathbf{1 9}, \mathbf{2 0})}$

Enamel hypocalcification may affect a single tooth if the insult is localized (e.g., infection from

a fractured deciduous tooth, iatrogenic from inelegant deciduous tooth extraction, bruising from local facial trauma). Many systemic conditions, such as pyrexia, hypoproteinemia, epitheliotrophic virus infection can cause widespread enamel hypocalcification on those areas of many teeth that were undergoing amelogenesis during the time of the illness. ${ }^{(21)}$ However, enamel hypoplasia defined as an incomplete or defective formation of the organic enamel matrix of teeth during the formative stage, the enamel matrix formation does not take place. Clinically dental hypoplasia shows complete or partial lack of enamelformation. ${ }^{(\mathbf{1 9})}$

\section{MATERIALS AND METHODS}

\subsection{The sample}

This study was conducted on (1000) of schools children, (500) boys and (500) girls with an age ranged from 4 to 12 years. It was conducted at preschools and primary schools children in different locations of Sana'a city in Republic of Yemen according to a recent geographical map.

\subsection{Examination of Children}

Before the examination started, The examiners gave information for the students about the teeth and gave them some instructions about the preservation of the teeth and complications due to irregular brushing. Children who agreed to participate in this study by consent from the parents were examined at the schools during class hours at their desks in the classroom, in a predetermined timetable, as arranged with the schools principals. Each child was examined to detect the dental anomalies in the natural light with a disposable mouth mirrors, using gloves and gauze pads. A data collecting chart was designed for recording the necessary information's for each child including personal data as name, age, sex and birth date. For each child who displayed apparent dental anomaly, the medical was reported in order to get the information regarding the cause related to the dental anomaly.

\section{RESUlts}

This study was conducted to evaluate the prevalence of dental anomalies among schools children in Sana'a city, with age ranged from 4-12 years. The sample size included 1000 children randomly selected through cluster sampling, 500 boys (50\%) and 500 girls (50\%) respectively.

Distribution of dental anomalies according to gender is summarized in table, which

shows the following results:

Dental anomalies were seen in 77 child (7.7\%).The number of dental anomalies in boys was 58 $(5.8 \%)$ and $19(1.9 \%)$ in girls.

The percentage of the dental fusion was $0.2 \%$ and the percentage of the dental gemination was also $0.2 \%$ in boys only.

The total percentage of dental transposition was $(0.3 \%)$ with percentage $(0.1 \%)$ in boys and $(0.2 \%)$ in girls. Dental transposition was more common in the maxilla than in the mandible, especially the maxillary canine-lateral incisor region.

The percentage of supernumerary teeth was $(0.3 \%)$ in boys only, where they observed in the permanent dentition, and more evidence in the anterior region as mesiodense. 
The percentage of hypodontia was $(0.2 \%)$ in boys and $(0.2 \%)$ in girls with total percentage $(0.4 \%)$. The maxillary lateral incisors were the most frequently absent teeth in both sexes.

Macrodontia was detected only in the anterior region in 3 cases $(0.3 \%)$ in boys and one case $(0.1 \%)$ in girls. The total percentage was 4 cases $(0.4 \%)$, figure (1). While, microdontia was also detected in the anterior region in 3 cases $(0.3 \%)$ in boys and 2 cases $(0.2 \%)$ in girls. The total percentage was 5 cases (0.5\%), figure (2).

Enamel hypocalcification was observed in 26 children, 22 boys $(2.2 \%)$ and 4 girls $(0.4 \%)$ with total percentage $(2.6 \%)$, figure (3).While, the percentage of enamel hypoplasia was $20(2 \%)$ in boys and $(0.8 \%)$ in girls with total percentage $(2.8 \%)$, figure (4).

Table. Distribution of Dental Anomalies According to Gender

\begin{tabular}{|c|c|c|c|}
\hline \hline Gender & Boys & Girls & Total \\
\hline Dental anomalies & $2(0.2 \%)$ & $0(0 \%)$ & $2(0.2 \%)$ \\
\hline Dental fusion & $2(0.2 \%)$ & $0(0 \%)$ & $2(0.2 \%)$ \\
\hline Dental gemination & $1(0.1 \%)$ & $2(0.2 \%)$ & $3(0.3 \%)$ \\
\hline Dental transposition & $3(0.3 \%)$ & $0(0 \%)$ & $3(0.3 \%)$ \\
\hline Supernumerary teeth & $2(0.2 \%)$ & $2(0.2 \%)$ & $4(0.4 \%)$ \\
\hline Hypodontia & $3(0.3 \%)$ & $1(0.1 \%)$ & $4(0.4 \%)$ \\
\hline Macrodontia & $3(0.3 \%)$ & $2(0.2 \%)$ & $5(0.5 \%)$ \\
\hline Microdontia & $22(2.2 \%)$ & $4(0.4 \%)$ & $26(2.6 \%)$ \\
\hline Enamel hypocalcification & $20(2 \%)$ & $8(0.8 \%)$ & $28(2.8 \%)$ \\
\hline Enamel hypoplasia & $58(5.8 \%)$ & $19(1.9 \%)$ & $77(7.7 \%)$ \\
\hline Total & \multicolumn{2}{|}{}
\end{tabular}

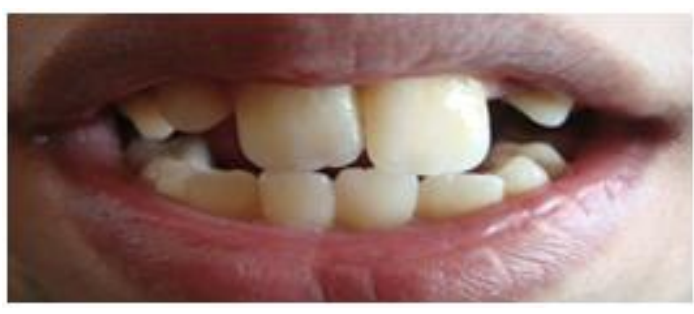

Fig1.Photograph showing macrodontia of the maxillary permanent central incisors

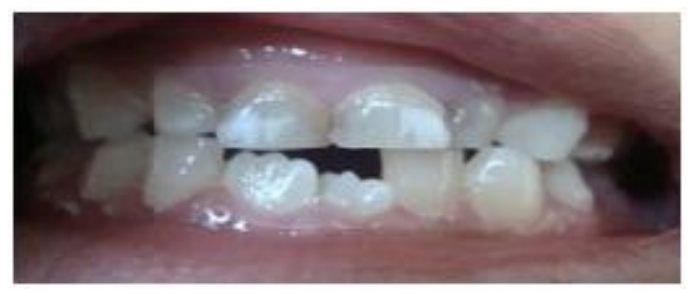

Fig3. Photograph showing enamel hypocalcifi cation of the maxillary deciduous incisors

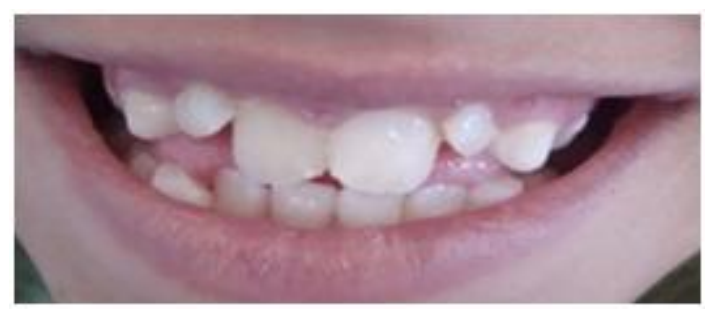

Fig2. Photograph showing microdontia of the maxillary permanent lateral incisors.

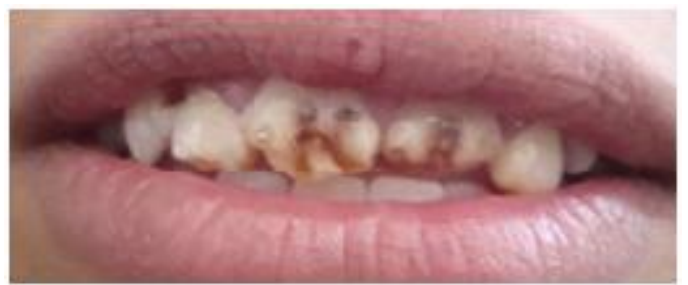

Fig4. Photograph showing enamel hypoplasia of the maxill ary permanent incisors

\section{DisCUSSION}

Study of the most common dental anomalies is important for accurate and effective treatment planning. Although there have been several studies reporting the prevalence of dental anomalies, no reported study has been conducted on Yemeni children.

In the present study, there was a gender predilection of dental anomalies, with the higher prevalence in boys. The number of dental anomalies was $58(5.8 \%)$ in boys and $19(1.9 \%)$ in girls. The reason for this difference was related to ethnic and racial factors. This is in agreement with earlier reports from Taranaki by Whittington and Durward $(1996)^{(22)}$, and from Saudi Arabia by Osuji and Hardie (2002) ${ }^{(2)}$. These results in disagreement with Thongudomporn and Freer $(1998)^{(23)}$, who 
reported that dental anomalies occurred more frequently in girls thanboys, this can be attributed to the sample size ( 65 girls and 46 boys).

The prevalence of dental fusion in this study was (0.2\%). This is in agreement with Ishida et al.,(1990) ${ }^{(24)}$; Skrinjaric and Barac-Furtinovic $(1991)^{(25)}$; Whittington and Durward (1996) ${ }^{(22)}$; Malcic and Prpic-mehicic $(2005)^{(7)}$, but is not in agreement with Osuji and Hardie (2002) ${ }^{(2)}$; Kramer et al.,(2008) ${ }^{(26)}$, who found the prevalence of dental fusion $1.3 \%$ and $3.7 \%$ respectively. This might be attributed to difference in sample size (1260 children).

The prevalence of dental gemination in this study was $0.2 \%$ which is near to the findings of Skrinjaric and Barac-Furtinovic(1991) ${ }^{(25)}$ which was $(0.4 \%)$, Whittington and Durward $(1996)^{(22)}$ which was $(0.4 \%)$, Backman and Wahlin (2001) ${ }^{(27)}$ which was $(0.3 \%)$. Dental germination was found in boys, this can related to the great activities and sports occurring in boys more than girls at this age period which lead to traumaoccurring to the deciduous teeth and during development of the tooth germ of the permanent successor according to Hattab and Hazzaa, (2001) ${ }^{(10)}$; Tomazinho et al., (2009) $)^{(28)}$.

The prevalence of dental transposition in the present study was $(0.03 \%)$, and showed a high girls predilection. This is in agreement with Ghaznawi et al., (1999) ${ }^{(29)}$; Shapira and Kuftinec (2001) ${ }^{(30)}$; Yilmaz et al., (2005) $)^{(\mathbf{3 1})}$. This can be related to hereditary or a genetic etiology, migration of a tooth during formation, and trauma to the deciduous teeth has also been suggested as a factor in this case.

Supernumerary teeth were observed in $0.3 \%$ of our subjects which is in agreement with Kramer et al.,(2008) ${ }^{(\mathbf{2 6})}$ which was $(0.3 \%)$ among 1260 Brazilian children, but is significantly less than what was found by Garvey et al.,(1999) ${ }^{(32)}$ which was $(2.1 \%)$, Backman and Wahlin (2001) ${ }^{(27)}$ which was (1.9\%), Miziara et al., $(\mathbf{2 0 0 8})^{(\mathbf{3 3})}$ which was $(2.3 \%)$. This can be related to difference in sample size or hereditaryetiology.Supernumerary teeth weremore frequently in boys than girls, these results are in agreement with previous studies as Skrinjaric and Barac-Furtinovic $(1991)^{(25)}$; Fazliah(2007) ${ }^{(16)}$. Supernumerary teeth were more frequently in the permanent dentition, more so in the anterior region as mesiodense than any part of either dental arch, this is in agreement with Backman and Wahlin $(2001)^{(27)}$, this can be related to hypergenesis of the epithelial cord, hereditary, and splitting of permanent tooth germ.

In the present study, hypodontia was observed in $0.4 \%$ of study sample which is near to the findings of Kramer et al., (2008) ${ }^{(\mathbf{2 6})}$ in Brazil (0.6\%), but is significantly less than the findings of Backman and Wahlin (2001) ${ }^{(27)}$ which was $(7.4 \%)$, this can be related to hereditary or a genetic etiology. The maxillary lateral incisors were the most frequently absent teeth equally in both sexes, but in other studies, the developmental absence of the upper lateral incisors has been shown to be more common in girls as reported by Johannsdottir et al., $(1997)^{(34)}$; Pinho et al. $(\mathbf{2 0 0 5})^{(35)}$, the reasons for this consistent gender difference are not clear, and may be related to hereditary and racial factors.

The prevalence of macrodontia was $(0.4 \%)$. So, the finding of this study is near to that of Backman and Wahlin $(2001)^{(27)}$; Ghaznawi et al., (1999) ${ }^{(29)}$ which were $0.2 \%$, and $0.5 \%$ respectively. Ghaznawi et al., (1999) ${ }^{(\mathbf{2 9 )})}$ in their study of clinical survey of selected dental anomalies in a Saudi Arabian population stated that: "macrodontia was observed in the anterior teeth only". This is in accordance with the present study. The importance of hereditary factors must be considered.

The prevalence of microdontia was $0.5 \%$. It was found only in the anterior region, and occurred in both maxillary and mandibular arches, as found by Kramer et al.,(2008) ${ }^{(\mathbf{2 6})}$. This may be a result of the role of hereditary factors.

The prevalence of enamel hypocalcification in this study was $2.6 \%$, and represented the $2^{\text {nd }}$ common type of dental anomalies. This is in agreement with Kellerhoff and Lussi (2004) ${ }^{(36)}$, who reported that enamel hypocalcification of the enamel was one of the most common dental anomalies, but it is significantly less than what was found by Aminabadi et al.,(2009) ${ }^{(37)}$ which was $(23.96 \%)$, this can be related to difference in sample size and hereditary etiology.

In the present study, the prevalence of enamel hypoplasia was $2.8 \%$ and represented the $1^{\text {st }}$ common type of dental anomalies. This can be attributed to local infections or systemic disturbances during 
childhood illnesses, and may occur due to other reasons such as nutritional deficiencies as vitamins A, $\mathrm{C}$, and D, Calcium, or related to $\mathrm{X}$ radiation as reported by $\boldsymbol{R a o}(\mathbf{2 0 0 8})^{(\mathbf{2 0 )}}$. It is significantly higher than what was found by Yonezu et al., (1997) ${ }^{(38)}$ in Japan, which was $(1.5 \%)$, and lower than what was found by Ishida et al., (1990) ${ }^{(24)}$ which was (5.2\%); Miziara et al., (2008) ${ }^{(33)}$ in Brazil which was $(3.5 \%)$, this can be related to difference in sample size and hereditary etiology.

\section{CONCLuSION}

It may be concluded that dental anomalies were seen in $15.1 \%$ of schools children and frequented in males more than females. Enamel hypoplasia was the commonest dental anomaly, while the lowest dental anomalies were dental fusion and gemination.

\section{REFERENCES}

[1] Katinka R. Prevalence and treatment possibilities of numerical, morphological dental anomalies and malposition during childhood. Ph. D. Thesis, Faculty of Dentistry, University of Szeged, Szeged, Hungary, 2008.

[2] Osuji O , Hardie J. Dental anomalies in a population of Saudi Arabian children in Tabuk. Saudi Dental Journal 2002; 14:11-4.

[3] Mojarrad F, Vaziri P. Prevalence of Tongue Anomalies in Hamadan, Iran. Iranian J publ Health 2008; 37(2):101-5.

[4] Turkaslan S , Gokce H, Dalkiz M. Esthetic Rehabilitation of Bilateral Geminated Teeth: A Case Report. European Journal of Dentistry 2007;1(3):188-91.

[5] Nunes E, Moraes I, Novaes P, Sousa S. Bilateral Fusion of Mandibular Second Molares with Supernumerary Teeth: Case Report.Braz Dent J 2002; 13(2):137-41.

[6] Desiqueira V, Braga T, Martins MA, Raitz R , Martins MD. Dental fusion and dens evaginatus in the permanent dentition: Literature review and clinical case report with conservative treatment. J Dent Child 2004; 71(1):69-72.

[7] Malcic A, Prpic-Mehicic G. Conservative Treatment of Fused Teeth in Permanent Dentition. Acta. Stomatol Croat 2005; 39(3):327-8.

[8] Asgary S. Endodontic treatment of a maxillary second molar with developmental anomaly: A case report. Iranian Endodontic Journal 2007; 2 (2):73-6.

[9] Santos K , Lins C , Fabio Almeida-Gomes F , Travassos R , Santos R. Anatomical Aspects of Permanent Geminate Superior Central Incisors. Int. J. Morphol 2009; 27(2):515-7.

[10] Hattab F, Hazzaa A. An Unusual Case of Talon Cusp on Geminated Tooth. J Can Dent Assoc 2001; 67:263-6.

[11] Hernandez-Guisado J, Torres-Lagares D, Infante-Cossio P, Gutierrez-Perez J.Dental gemination: Report of case. Med Oral 2002; 7(3):231-6.

[12] Agnihotri A, Marwah N, Goel M. Geminated Maxillary Lateral Incisor with Talon Cusp: A Rare Case Report. J Oral Health Comm Dent. 2007; 1(2):40-2.

[13] Kayipmaz S, Saricaoglu S, Sezgin O. Unusual teeth transpositions: two case reports. Oral Radiol 2009; 25:81-4.

[14] Sholapurkar A. Incisor Transposition. British Dental Journal 2008; 204(11):598.

[15] Fareed A. Supernumerary Teeth. The Catalogue for Transmission Genetics in Arabs CTGA Database. Center for Arab Genomic Studies, 2006; pages: 1-2.

[16] Fazliah S. Supernumerary tooth: report of a case. Archives of Orofacial Sciences 2007; 2:54-8.

[17] Kindelan J, Rysiecki G , Childs W. Hypodontia: Genotype or Environment?: A Case Report of Monozygotic Twins. British Journal of Orthodontics 1998; 25:175-8.

[18] Ohno K, Ohmori I. Anodontia with hypohidrotic ectodermal dysplasia in a young female: A case report. Pediatric. Dentistry 2000; 22(1): 49-52.

[19] Chandra S, Shaleen C. Developmental Disturbances in Dentition and Surrounding Structures, Textbook of Pedodontics, Jaypee Brothers Medical Publishers,1st edition, 2002; pages:40-3.

[20] Rao A.(2008): Growth and Development In: Principles and Practice of Pedodontics. Jaypee Brothers Medical Publishers, 2nd edition, 2008; pages: 44-66. 
[21] Hale F. Nutritional Impactions in $19^{\text {th }}$ Century Portugal: A LEH Study of Frequency and Duration. M.D. Thesis, Faculty of Art, North Carolina State University , USA, 2012.

[22] Whittington B, Durward S. Survey of anomalies in primary teeth and their correlation with the permanent dentition. N Z Dent J 1996; 92(407):4-8.

[23] Thongudomporn U, Freer T. Prevalence of dental anomalies in orthodontic patients. Australian Dental Journal 1998; 43(6):395-8.

[24] Ishida R, Mishima K, Adachi C, Miyamoto A , Ooshima T, Amari E, Kamiyama K, Higaki M, Akasaka M, Yoshida S. Frequency of the developmental disturbances of tooth structure. Shoni Shikagaku Zasshi 1990; 28(2):466-85.

[25] Skrinjaric I, Barac-Furtinovic V. Anomalies of deciduous teeth and findings in permanent dentition. Acta Stomatol Croat 1991; 25(3):151-6.

[26] Kramer P, Feldens C, Ferreira S, Spiguel M, Feldens E. Dental anomalies and associated factors in 2-to 5 year old Brazilian children. Int J Paediatr Dent 2008; 18(6):434-40.

[27] Backman B, Wahlin Y. Variations in number and morphology of permanent teeth in 7 year-old Swedish children. Int J Paediatr Dent 2001; 11(1):11-7.

[28] Tomazinho F , Baratto-Filho F, Leonardi D, Haragushiku G, de Campos E. Occurrence of talon cusp on a geminated maxillary central incisor: a case report. Journal of Oral Science 2009; 51(2):297-300.

[29] Ghaznawi H, Daas H, Salako N. A Clinical and Radiographic Survey of Selected Dental Anomalies and Conditions in Saudi Arabian Population. Saudi Dental Journal 1999;11(1):8-13.

[30] Shapira Y, Kuftinec M. Maxillary tooth transposition: Characteristic features and accompanying dental anomalies. Am J of Orthod Dentofacial Orthop 2001; 119:127-34.

[31] Yilmaz H, Turkkahraman H, Sayin M. Prevalence of tooth transpositions and associated dental anomalies in a Turkish population. Dentomaxillofacial Radiology 2005; 34:32-5.

[32] Garvey M, Barry H, Marielle B. Supernumerary Teeth -An Overview of Classification, Diagnosis and Management. J Can Dent Assoc 1999; 65:612-6.

[33] Miziara R, Mendes-Junior C, Wiezel C, Simões A, Scuoteguazza J, Azoubel R. A Statistical Study of the Association of Seven Dental Anomalies in the Brazilian Population. Int. J. Morphol 2008; 26(2):403-6.

[34] Johannsdottir B, Wisth P, Magnusson T. Prevalence of malocclusion in 6-year-old Icelandic children. Acta Odontologica Scandinavica 1997; 55:398-402.

[35] Pinho T, Tavares P, Maciel P, Pollmann C. Developmental absence of maxillary lateral incisors in the Portuguese population. European Journal of Orthodontics 2005; 27(5):443-9.

[36] Kellerhoff N, Lussi A. Molar-incisor hypomineralization.Schweiz Monatsschr Zahnmed 2004; 114 (3):243-53.

[37] Aminabadi N, Oskouei S, Pouralibaba F, Jamali Z, Pakdel F. Enamel defects of human primary dentition as virtual memory of early developmental events. Journal of Dental Research 2009; 3(4):110-6.

[38] Yonezu T, Hayashi Y, Sasaki J, Machida Y. Prevalence of congenital dental anomalies of the deciduous dentition in Japanese children. Bull Tokyo Dent Coll 1997; 38(1):27-32. 